DOI 10.31418/2177-2770.2019.v11.n.30.p26-38 | ISSN 2177-2770

Licenciado sob uma Licença Creative Commons

\title{
(c) $(1)$ \\ NEGOS PRETOS EM LINHA DE PASSE: UMA LEITURA SOBRE A TAÇA DAS FAVELAS
}

\author{
Monica da Silva Francisco ${ }^{1}$
}

Resumo: Este artigo traça um olhar sobre a inserção de jovens negros no Campeonato Taça das Favelas, evento organizado pela Central Única de Favelas, discutindo as mudanças ocorridas com a modernização do futebol e as dificuldades de mobilidade social que trouxe aos jovens negros periféricos que veem no futebol uma possibilidade de adentrarem no universo do esporte profissional. Trazendo algumas considerações sobre as juventudes negras masculinas, patriarcado e masculinidades.

Palavras-chave: juventude; raça; racismo; Taça das Favelas; masculinidades;

\section{NEGOS BLACKS IN THE PASS LINE: A READING ON THE BOWL OF THE SLUMS}

Abstract: This article addresses the very reality coming from the insertion of black youth in the Taça das Favelas Championship, an event organized by the Central Única das Favelas (CUFA) in Rio de Janeiro, discussing the shifts arising from the modernization of soccer, as well as the difficulties of achieving social mobility black and people from periphery still face in football currently, such as the few possibilities those young black people face to enter the universe of professional sport. By arguing these points I thus bring some considerations about black male youths, patriarchy and masculinities.

Key-words: youth, race, racism, Championship, masculinities

\section{NEGOS NOIRS DANS LE PASSAGE DE LIGNE: UNE LECTURE SUR LE BOL DES BIDONVILLES}

Résumé: Cet article retrace l'insertion de jeunes Noirs dans le Taça das Favelas, un événement organisé par le Central Single de Favelas, discutant des changements survenus au cours de la modernisation du football et des difficultés de mobilité sociale qui ont amené de jeunes Noirs périphériques qui voient le football. une possibilité d'entrer dans l'univers du sport professionnel. Apportant quelques considérations sur les jeunes hommes noirs, le patriarcat et les masculinités.

Mots-clés : jeunes, Race, racisme, Bol de bidonvilles, de masculinités.

\footnotetext{
${ }^{1}$ Mestra e Doutoranda em Educação. PPgeduc UFRRJ. Graduada em Letras Pedagogia- Unisuam. E-mail: amonicafrancisco@gmail.com
}

Revista da ABPN・v. 11, n. 30・ set - nov 2019, p. 26-38 
NEGOS NEGROS EN LA LÍNEA DE PASE: UNA LECTURA SOBRE EL CUENCO DE LAS BARRIADAS

Resumen: Este artículo esboza una mirada acerca de la inserción de jóvenes negros en el trofeo del campeonato en los barrios bajos, un evento organizado por la Central Única de favelas, discutiendo los cambios con la modernización del fútbol y las dificultades de movilidad social que trajo a los jóvenes negros de los periféricos que ve en el fútbol una posibilidad de adentrarem el mundo del deporte profesional. Trayendo algunas consideraciones sobre el negro de los hombres jóvenes, el patriarcado y la masculinidad. juventud,

Palabra-clave: la raza, el racismo, el recipiente de los barrios de tugurios, la masculinidad

\section{INTRODUÇÃO}

Neste trabalho temos por objetivo tecer algumas considerações sobre a inserção de jovens negros no futebol, usando como referência a Taça das Favelas ${ }^{2}$. A partir desse evento pensar como a inserção dos jovens negros nesse esporte e sua relação com masculinidades juvenis, especialmente no tocante ao papel do patriarcado dentro das famílias negras em que o modelo do homem como provedor alcança meninos pobres que vivem em áreas periféricas e abandonadas pelo Estado. Desse modo, debateremos alguns pontos fundamentais para a compreensão do fenômeno, tais como: futebol como coadjuvante na formação social desses sujeitos o processo de juventude e as relações entre o patriarcado a formação de masculinidades negras.

Nosso referencial teórico está fundamentado nas discussões de Gênero, Relações Étnico-raciais e Juventudes e nossos métodos e técnicas utilizados foram o levantamento bibliográfico e revisão de literatura. A metodologia da pesquisa utilizada na tessitura do artigo é composta de revisão de literatura, após um levantamento bibliográfico sobre a Taça das Favelas, futebol, juventudes negras masculinas, associada a assistência de vídeos que versem sobre a inserção de jovens negros nos times de base.

Observamos durante a realização da revisão de literatura a existência de uma pequena quantidade de literatura que abordem o processo de formação de masculinidades de jovens negros periféricos e sua inserção nos esportes coletivos.

\footnotetext{
${ }^{2}$ https://www.tacadasfavelas.com.br/
} 
O trabalho está organizado do seguinte modo: na primeira parte tecemos uma abordagem sobre a Taça das Favelas e o futebol, na segunda parte elaboramos alguns, apontamentos sobre patriarcado, juventudes negras e masculinidades.

\section{EM LINHA DE PASSE}

No vídeo-reportagem intitulada Diogo, o artilheiro que ressurgiu na Taça das Favelas graças ao futebol ${ }^{3}$ publicada no jornal digital globoesporte.globo.com conta a narrativa do jovem de cor preta morador da favela de Campo Grande no Rio de Janeiro que se reinseriu na sociedade por meio do futebol. O jovem conta que poderia ter sido preso ou estar morto mas que o futebol foi o grande motivador para que ele saísse do tráfico de drogas pois sendo considerado um jogador talentoso pelos técnicos do time, ele buscava apenas uma oportunidade de ajudar a família a sair da pobreza e considera o campeonato uma espécie de vitrine para mostrar seu talento. O relato do rapaz nos permite a reflexão sobre a importância do futebol dentro do imaginário juvenil sobre a ascensão social de negros por meio do esporte.

O Campeonato de Futebol nomeado Taça das Favelas criado em 2012 é um dos mais importantes eventos esportivos juvenis do país, organizado pela Central Única de FavelasCUFA é considerado o maior torneio de favelas do mundo. Segundo informações do site, o evento busca "inclusão social através do esporte, influenciando positivamente a realidade de crianças e jovens brasileiros" e uma "oportunidade de revelação de novos talentos para o futebol". Na descrição do site, o torneio "visa contribuir para a promoção da inclusão social através do esporte, influenciando positivamente a realidade de crianças e jovens brasileiros, objetivando "a integração das comunidades, a ressignificação dos territórios e o fortalecimento da autoestima das juventudes da favela". No ano de 2019, o evento reuniu 200 mil jovens divididos em times de jogadores do sexo masculino e feminino de todos os estados brasileiros que integram as equipes de futebol. $\mathrm{Na}$ pesquisa nos interessa a

\footnotetext{
${ }^{3}$ https://globoesporte.globo.com/eventos/taca-das-favelas/noticia/diogo-o-artilheiro-que-ressurgiu-na-tacadas-favelas-gracas-ao-futebol.ghtml
} 
participação dos rapazes negros como pano de fundo para pensarmos as relações tecidas entre os jovens pretos, futebol e masculinidades.

No artigo Quero ser jogador de futebol: um ensaio sobre o perfil de jovens de comunidades que participam do torneio taça nas favelas da Cufa, em 2012 a pesquisadora Ana Lucia Guimarães traçou um perfil sobre os participantes da Copa das Favelas, segundo a autora o torneio reúne jovens moradores de favelas do Rio de Janeiro e Baixada Fluminense, maiores de 18 anos, desempregados que não possuíam o Ensino Médio completo. A pesquisa apontou a predominância de jovens pretos e pardos que "revela a face da realidade social que reforça mais uma vez a associação do estereótipo social: a associação entre cor da pele e busca de ascensão social por meio do esporte, que no caso é o futebol" (Guimarães, 2012, p. 3). Na concepção de Campos (2018):

O corpo do jovem negro está associado à inferiorização do ponto de vista social e é criminalizado. O outro olhar, que parte também pelo estereótipo, é o de possibilidade de atuação no esporte, pois esse corpo é visto como robusto, forte, talhado e apto para a prática esportiva, sobretudo em alto rendimento." (...) "Temos na atividade esportiva em geral, sobretudo na de alto rendimento, um caminho que não é o melhor, mas é um caminho - para se superar uma situação muito difícil na sociedade, que é o genocídio de jovens e adolescentes negros, sobretudo em situação subalterna e na periferia”.(CAMPOS, 2018, p. $3)$.

No discurso do pesquisador fica evidente a percepção do tratamento diferenciado que os jovens negros sofrem em relação aos seus pares brancos e o papel do racismo na classificação de sujeitos em raças diferenciadas desenvolvidas pelas teorias racialistas do século XXVII que embora tenham caído em descrédito após o reconhecimento da não existência de raças, continua vigente no imaginário social e na categorização dos corpos negros nos esportes. Campos (2018, p.3) argumenta que em certos desportos como o futebol, a sociedade normatiza a existência de negros, apesar disso em categorias "como tênis, esportes náuticos, automobilismo ou até mesmo o vôlei terá fronteira racista e de classe, pois o racismo no Brasil é estrutural e a gente tem [isso] no esporte”.

O mundo do futebol, embora aparente ser uma instituição apartada da realidade, é agregado e influenciado por um amálgama de ideias, valores, ambições, frustrações, tabus, regras, normas, sublimações, memórias, entre outras, que motivam e envolvem projetos individuais e coletivos à sua própria dimensão e potencialidade. E, por ser aparentemente apartado da realidade social, funciona como catalisador de 
quantidade considerável de massa jovem independentemente de classe social afinado com os sonhos e as ilusões produzidas pelos benefícios da fama, sucesso e status do jogador bem sucedido no futebol profissional (CAMPOS, 2018, p. 3).

Guimarães (2012, p.4) observa que a teoria do futebol como instrumento de ascensão social de homens jovens pobres no Brasil independente de escolaridade e classe, presentes na década de 80 e 90 foi modificada com a inserção de jovens de outros perfis socioeconômicos matriculados em escolinhas de futebol, da diminuição dos campos de várzea com o aumento da especulação imobiliária e da aplicação de novas tecnologias no futebol. No artigo "As transformações na estrutura do futebol brasileiro: o fim das torcidas organizadas nos estádios de futebol", Pimenta (2000) discorre sobre as mudanças decorrentes no futebol nas últimas décadas.

A formação dos jogadores, antes oriundos de campos de várzea e terrenos baldios, é feita, hoje, nas escolinhas de futebol vinculadas ou não a um clube em que a família do jovem atleta arca com as mensalidades e em clubes-empresa que servem de "laboratórios" para teste de mercadorias (atletas) tendo como patrocinador a figura do empresário de futebol. As escolinhas sepultam a malandragem e a alegria do futebol nacional tornando-o subordinado a táticas e estratégias que exigem disciplina e obediência a esquemas rigorosos e sofisticados (PIMENTA, 2000, p.131).

A mudança de cenário social na construção do jogador de futebol, orientadas pelas diretrizes propostas pela mercantilização do esporte, em que o atleta passa a ser construído dentro de um espaço forjado, diferente do "futebol-arte,uma das peculiaridades brasileiras desenvolvidas por jogadores negros e mestiços” (Lopes, 1998). Rodrigues (2004) no artigo Modernidade, disciplina e futebol: uma análise sociológica da produção social do jogador de futebol no Brasil traça uma leitura sobre o trabalho do jogador de futebol, usando como referencial teórico a teoria disciplinar de Michel Focault (2001) para analisar os métodos utilizados na formação de jogadores na categoria base (juvenil e junior) e profissional do time Sport Club Internacional de Porto Alegre, Rio Grande do Sul. O autor aponta

É necessário operacionalizar o corpo, tornar possível alcançar elevada performance desportiva. No treinamento esportivo, o corpo aparece como um objeto passível de manipulação, adestramento e operacionalidade, comparável a uma máquina. O corpo pode ser colocado em funcionamento; para isso, recebe treinamentos especiais. Trata-se de uma consciência mecânica do corpo no esporte. A teoria do treinamento desportivo pode

Revista da ABPN・v. 11, n. 30・ set - nov 2019, p. 26-38 
assemelhar-se a outras técnicas e outros discursos sobre o corpo, tais como os cuidados com dieta e estética (RODRIGUES, 2001, p.5).

$\mathrm{Na}$ perspectiva do autor, a disciplina exigida nos clubes de futebol condiciona os corpos dos jogadores visando melhorar a performance ao mesmo tempo que produz atletas mais capazes e habilidosos.

\section{JUVENTUDES MASCULINAS NEGRAS}

No Brasil, de acordo com o Estatuto da Juventude são considerados jovens, os indivíduos na faixa etária entre 15 e 29 anos e adolescentes, sujeitos entre 12 e 18 anos conforme o Estatuto da Criança e Juventude, (Lei n8069/90). Na concepção de Corti e Souza "essa distinção contribui para o aprimoramento do conhecimento sobre os jovens, descobrindo suas demandas, interesses e necessidades de cada momento. (Corti; Souza. 2004. p.25). Diogénes (2012) chama atenção ao fato que:

A juventude é um conceito que exige de quem pesquisa, e mais ainda de quem atua nesse campo de construção específica das políticas públicas, uma necessidade contínua de decifração. Ela representa uma condição que mais se define por suas práticas, por suas formas diversas de atuação e de experimentação do que mesmo por conceituações e referenciais estáveis e fixos (DIÓGENES, 2012, p. 104).

No texto, utilizaremos a ideia de condição juvenil, utilizada por Dayrell (2007) para compreendermos a maneira com que os grupos sociais imputam significações diferentes as juventudes no "contexto de uma dimensão histórico-geracional, mas também à sua situação, ou seja, o modo como tal condição é vivida a partir dos diversos recortes referidos às diferenças sociais - classe, género, etnia”. A partir dessa conceituação entendemos que categorias como gênero, classe e etnia são determinantes nos modos de vivenciar esse período da vida e que no caso dos jovens homens negros das camadas populares em que pesam o estigma da marginalidade como aponta Carrano (2019)

Representações essas que podem adquirir o caráter de estigma - imagem deteriorada -, quando se trata de jovens que não se encaixam no padrão branco, masculino e dominante de 
uma sociedade que se estruturou na base da desigualdade entre as classes sociais, sob a égide do patriarcalismo e por uma pesada herança escravocrata que, mesmo depois de mais de um século de abolição da escravatura, ainda incide negativamente sobre a população negra e indígena. A pobreza, a falta de oportunidades sociais e econômicas para jovens moradores de territórios empobrecidos, e a representação negativa, que transforma negros em alvos preferenciais das forças policiais, fazem com que o índice de assassinato de jovens negros seja superior a qualquer outra parcela da população (CARRANO, 2019, p.2).

A leitura proposta pelo autor nos impulsiona a compreender o papel das representações sociais sobre a juventude masculina negra, uma vez que o racismo reserva um espaço marginalizado para esses jovens de pele escura. De acordo com a Professora Anhamona de Brito (2018)

O ódio especificamente dirigido à juventude negra e masculina faz parte de uma seleção perversa que nega a este grupo dignidade, justiça social e, assina sua vida como mecanismo de subjugação e controle social, o qual blinda privilégios a uma minoria, os não-negros das elites, os quais sempre detiveram acesso ampliado aos bens sociais. A juventude negra masculina sofre com a ausência de acesso aos bens sociais - saúde, educação, lazer, trabalho e emprego, etc. Além disso, recebe nos peitos o impacto negativo do ódio historicamente estabelecido contra suas características fenotípicas. Ao saírem nas ruas, são os potenciais criminosos, aqueles a quem a sociedade fomenta o medo e, por consequência, o ódio. Sem acesso aos bens sociais, temidos e odiados, tornam-se alvos preferenciais sob a chancela, quando não a ação direta, do próprio Estado (Brito, 2018, p.2).

No artigo Pedagogia da crueldade: racismo e extermínio da juventude negra, as autoras Gomes e Laborne (2018) analisando os dados sobre as mortes dos jovens negros presentes no Atlas da Violência (2017) aborda a questão de gênero ao questionar o recorte de crueldade das maiorias dos extermínios serem de jovens homens negros. A partir dessa perspectiva passaremos a discutir brevemente as noções de gênero, patriarcado e racismo no contexto das famílias negras em que os jovens negros estão inseridos.

\section{A CONSTRUÇÃO DE MASCULINIDADES E PATRIARCADO}

No relato que iniciou o segundo capítulo, apresentei a narrativa de Diogo e suas expectativas de "vencer na vida" por meio do futebol, o jovem considerado um jogador habilidoso pelos treinadores do projeto social da favela Gogó da Ema conforme mostra a reportagem, via o Campeonato Taça das Favelas como a possibilidade de emprego e 
ascensão social por uma suposta contratação por um time de futebol que possibilitaria dar conforto material e tirar sua família da favela.

Depoimentos como de Diogo, revelam a face da exclusão da juventude masculina negra moradora de periferias e favelas de do Rio de Janeiro, áreas em que o Estado se mostra ausente não proporcionando áreas de lazer e sociabilidades para juventude (Junior, 2019). Nesses espaços de exclusão social, os modelos de masculinidades desenvolvidos pelos jovens dialogam como modelo do patriarcado em que o sujeito é mesmo sendo jovem, muitas das vezes ainda criança, por ter nascido do sexo masculino é considerado o chefe da família, sendo responsável pelo sustento e manutenção da casa, como mostram as pesquisas do Instituto Brasileiro de Geografia e Estatísticas (IBGE,2016) que apontam crianças e adolescentes negros do sexo masculino como as principais vítimas de trabalho infantil.

Ao mesmo tempo que refletem as teorias sobre masculinidades e o impacto do racismo nas existências de pessoas negras o que torna a construção da masculinidade juvenil negra diferenciada. De acordo com Junior (2019, p. 2).

\begin{abstract}
Racismo antinegro definido como uma ideologia de dominação e, como toda ideologia, camuflando as suas práticas, decorrendo do processo de encobrimento da realidade a dificuldade da população em reconhecer a existência de racismo no Brasil. O racismo antinegro é um problema estrutural das relações sociais brasileiras e as situações dos bairros negros são, em parte, consequência da forma de operação do racismo antinegro nas instituições e nas relações sociais. Parte significativa das vidas das populações negras é gerada pelo racismo estrutural e pelas condições da cidade produzida pelo mesmo racismo estrutural antinegro. (JUNIOR, 2019, p.4)
\end{abstract}

Na concepção da pesquisadora nigeriana Oyèrónké Oyěwùmí (2004) o conceito de gênero surge a partir da modernidade que introduziu uma série de processos históricos e transformações sociais e culturais como o "tráfico atlântico de escravos e instituições que acompanharam a escravidão, e a colonização europeia de África, Ásia e América Latina” (Oyěwùmí, 2004, p.1). Oyronke analisando a produção intelectual sobre mulheres e hierarquias de gênero afirma a que o "gênero tornou-se uma das categorias analíticas mais 
importantes na empreitada acadêmica de descrever o mundo e tarefa política de prescrever soluções". (Oyěwùmí, 2004, p.1)

Partindo dessa premissa, nos adverte que categorias como: mulher, família, relações sociais e corpo fundamentais dentro da epistemologia do feminismo branco são pensadas de modo diferentes quando se referem aos povos negros, uma reivindicação do feminismo afro americano que tem no trinômio gênero, raça e classe a centralidade de suas análises da sociedade. Na concepção da estudiosa:

A ideia que gênero é socialmente construído não é uma declaração de que a biologia é irrelevante ou que a natureza não conta. Em vez disso, a noção de construção social propõe como a biologia seja interpretada, e quais atributos biológicos contam, são questões culturais localizadas em como determinadas sociedades querem interpretar a biologia e certamente interpretar o que é biológico. Devemos lembrar que mesmo antes dos hormônios e da biologia de reprodução serem "descobertos", algumas sociedades já tinham noções muito decididas das diferenças naturais entre machos e fêmeas (OYĚWÙMÍ, 2017, p. 4).

Na concepção de Connel (2013)

As relações de gênero são sempre arenas de tensão. Um dado padrão de masculinidade é hegemônico enquanto fornece uma solução a essas tensões, tendendo a estabilizar o poder patriarcal ou reconstituí-lo em novas condições. Um padrão de práticas (isto é, uma versão de masculinidade) que forneceu soluções em condições anteriores, mas não em novas situações, é aberto ao questionamento - ele, de fato, será contestado (CONNEL, 2013, p. 54).

Connel (2016) assegura que o molde de masculinidade hegemônica cria um padrão de comportamento que norteia as ações de todos os indivíduos, sendo considerada a maneira mais celebrada de ser homem cobrando de todos os sujeitos se comportem a partir desse modelo que impõem a dominação dos homens sobre as mulheres.

Na concepção da autora, olhando a partir do modelo de sociedade contemporânea que os grupos masculinos não são privilegiados de forma igual dentro das estruturas do patriarcado e observa alguns pontos referentes a masculinidades.

[...] que vive na imaginação dos homens que se consideram membros desse grupo [...] aqueles que se constroem como tal, vivem a partir de um conceito imaginado de pertencer a 
uma mesma comunidade de masculinidade hegemônica que atravessa a história e as culturas (CONNEL, 2013, p.4).

Dialogando com os estudos de Connel (2013, 2016), Kimmel (1998) afirmam que as masculinidades são variáveis de acordo com o modelo de sociedade que o sujeito está imerso ao mesmo tempo que reconhece que as masculinidades têm significados diferentes para grupos de homens em diferentes momentos. A compreensão do modelo de masculinidade hegemônica presente no imaginário masculino permeia as vivências de rapazes negros pobres que muitas das vezes trabalham em empregos precarizados e são considerados desocupados. Embora esses jovens ocupem trabalhos informais como moto taxis, carregadores de caminhão, garçons em eventos, carroceiros, lavadores de carros, camelôs, etc. O olhar social sobre eles é que são delinquentes pois não estão enquadrados nas formas tradicionais de trabalho.

Na concepção de hooks o modelo de masculinidade dos jovens negros, está muito ligado aos valores europeus trazidos pelo patriarcado, de modo que os povos de origem africana inseridos nesse modelo cultural, são moldados dentro desse sistema. A pesquisadora hooks (2007) afirma:

O patriarcado é um sistema político-social que insiste que os homens são inerentemente dominantes, superiores a tudo e todos que são considerados fracos, especialmente as mulheres, e dotados do direito de dominar e governar sobre os fracos, e de manter esse domínio através de várias formas de terrorismo psicológico e violência.(...) Na igreja, eles aprenderam que Deus criou o homem para governar o mundo e tudo que existe nele, e que o trabalho das mulheres é de ajuda-los a cumprir estas tarefas, a obedecer e sempre assumir um papel subordinado em relação ao homem poderoso. Eles aprenderam que Deus é masculino. Estes ensinamentos foram reforçados por todas as instituições que eles encontraram - escolas, tribunais, clubes, arenas de esporte, assim como nas igrejas. Ao abraçar o pensamento patriarcal, como todas as outras pessoas ao redor deles, eles o ensinaram para seus filhos, porque parecia uma maneira "natural" de se organizar a vida (HOOKS, 2007, p. 68).

Na leitura de hooks, o patriarcado está ligado a violência e a dominação masculina e aponta a religião como mecanismo de difusão dessa ideologia, quando afirma que seus pais, aprenderam dentro da igreja sobre a superioridade do sexo masculino sobre o feminino, uma vez que "Deus era masculino" e as mulheres eram destinados um papel de 
subordinação ligados as ideologias religiosas. Embora a autora aborde uma a realidade afro- americana, percebemos muitas inferências com a realidade brasileira em que os jovens negros são muitas das vezes forçados pelas desigualdades sociais a tornarem-se arrimos de família ocupando-se em trabalhos legais ou ilegais por razões de subsistência.

Compreendemos que a noção do que seja "ser jovem homem negro" é atravessada por uma série de circunstâncias de violência institucional operadas pelo Estado que alimenta no imaginário social a ideia de marginalidade privando o jovem negro de vivenciar plenamente sua condição juvenil na medida que cerceiam seu trânsito pela cidade e ao mesmo tempo que a mídia opera cotidianamente a sua transmissão de estereótipos sobre a população negra.

\section{PARA ALÉM DAS CONSIDERAÇÕES FINAIS}

No artigo tecemos algumas considerações sobre a inserção de jovens negros no futebol utilizando como pano de fundo o Campeonato Taça das Favelas promovido pela Central Única de Favelas. O texto no parágrafo apresenta alguns dados sobre o futebol e as mudanças ocorridas nos últimos anos com a desvalorização do futebol- arte criado por negros e mestiços brasileiros em prol de uma "fabricação de atletas" dentro das escolinhas de futebol que mudou perfil dos jogadores racial, educativo e financeiro dos jogadores, uma vez que poucas famílias negras tem condições de manter suas crianças e jovens dentro desses espaços.

Compreendemos a importância de abordamos alguns pontos referentes as juventudes negras, apresentando o conceito de juventude e para melhor entendimento sobre as questões de gênero e raça apresentadas no texto, optamos pela utilização do termo "condição juvenil" por refletimos a importância da discussão de gênero, abordamos o sexo masculino e a raça negra, apontando como as vivências juvenis dos negros sofrem atravessamentos devido ao racismo presente na sociedade brasileira.

E finalizamos com uma breve discussão sobre o patriarcado e as masculinidades juvenis negras, uma vez que compreendemos que apenas as teorias européias não dão conta 
de entender as múltiplas realidades vivenciadas pelos jovens negros e que autores negros como bell hooks abordando o patriarcado e a discussão de Oyěwùmí sobre gênero possibilita um olhar mais amplo sobre o tema pois traz uma perspectiva que disputa a narrativa com a construção hegemônica sobre a temática.

\section{REFERÊNCIAS BIBLIOGRÁFICAS}

BRASIL. IBGE. Pesquisa Nacional por amostra de domicílios. 2016. IBGE, 2016.

BRITO. Anhamona. Entrevista. Racismo determina quem vai viver ou morrer na nossa sociedade', diz pesquisadora. [jun.2018]. Disponível em: https://www.correio24horas.com.br/noticia/nid/racismo-determina-quem-vai-viver-ou-morrer-nanossa-sociedade-diz-pesquisadora/. Acesso 10jul.2019.

CAMPOS, Flavio de. Entrevista "O futebol expressa dilemas e contradições da sociedade", diz pesquisador Flávio de Campos. [jul.2018]. Disponível em:https://portal.aprendiz.uol.com.br/2018/06/13/o-futebol-expressa-dilemas-e-contradicoes-dasociedade-diz-pesquisador-flavio-de-campos/. Acesso em 11.ago.2019.

CARRANO, Paulo. O jovem brasileiro e a escola diante da precarização da vida e de desafios democráticos. Observatório da Juventude.04.set 2019. Disponível em: https://www.observatoriodajuventude.org/o-jovem-brasileiro-e-a-escola-diante-da-precarizacao-davida-e-de-desafios-democraticos/. Acesso em: 15 de set.2019.

CONNELL, Robert W.; MESSERSCHMIDT, James W.. Masculinidade hegemônica: repensando o conceito. Rev. Estud. Fem., Florianópolis, v. 21, n. 1, p. 241-282, Apr. 2013.

DAYRELL, Juarez. A escola "faz" as juventudes? Reflexões em torno da socialização juvenil. Educ. Soc., Campinas,v. 28, n. 100, especial, p. 1105-1128, out. 2007.

DIÓGENES, Glória. Juventudes, violência a e políticas públicas no Brasil: tensões entre o instituído e o instituinte. Sinais Sociais, v. 1, p. 102-123, 2012.

DIOGO, o artilheiro que ressurgiu na Taça das Favelas graças ao futebol. Globoesporte.globo.com. Rio de Janeiro.17.jul.2019.Taça das Favelas. Disponível em:https:/globoesporte.globo.com/eventos/taca-das-favelas/noticia/diogo-o-artilheiro-queressurgiu-na-taca-das-favelas-gracas-ao-futebol.ghtml. Acesso.20. jul.2019.

GUIMARÃES, Ana Lúcia. Quero ser jogador de futebol: um ensaio sobre o perfil de jovens de comunidades que participam do Torneio Taça nas Favelas da CUFA. Corpus et Scientia, 2012.

HOOKS, Bell. The Will to Change: men, masculinity, and love. 2007. 
JUNIOR, Henrique Cunha. Bairros negros: a forma urbana das populações negras no brasil. Revista da Associação Brasileira de Pesquisadores/as Negros/as (ABPN), [S.1.], v. 11, n. Ed. Especi, p. 65-86, maio 2019. ISSN 2177-2770. Disponível em: $<$ http://www.abpnrevista.org.br/revista/index.php/revistaabpn1/article/view/683>. Acesso em: 16 set. 2019.

LOPES, J. S. L. Futebol Mestiço. Ciência Hoje, SBPC, v.24, nº 139, junho 1998.

KIMMEL, Michael S. "A produção simultânea de masculinidades hegemônicas e marginais". Horizontes Antropológicos: Corpo Doença e Saúde, v. 9, n. 1, p. 103-118, 1998. MISKOLCI, Richard.

OYĚWÙMÍ, Oyèrónké. Conceituando o gênero: os fundamentos eurocêntricos dos conceitos feministas e o desafio das epistemologias africanas. Tradução para uso didático de: OYĚWÙMÍ, Oyèrónké. Conceptualizing Gender: The Eurocentric Foundations of Feminist Concepts and the challenge of African Epistemologies. African Gender Scholarship: Concepts, Methodologies and Paradigms. CODESRIA Gender Series. Volume 1, Dakar, CODESRIA, 2004, p. 1-8 por Juliana Araújo Lopes.

PIMENTA, C. A. M. Novos Processos de Formação de Jogadores de Futebol e o fenômeno das. 'escolinhas': uma análise crítica do possivel. In: ALABARCES, Pablo (comp.). Peligro de gol: estudios sobre deporte y sociedad em 14América Latina. Buenos Aires: CLACSO, 2000. p. 75-97. Disponível Acesso:12/09/2019.

RODRIGUES, Franciso Xavier Freire. Modernidade, disciplina e futebol: uma análise sociológica da produção social do jogador de futebol no Brasil. Sociologias, Porto Alegre, n.11, p. 260-299, June 2004.

VALENTIN, Renato Beschizza. COELHO, Marília Martins. Sobre as escolinhas de futebol: o processo civilizador e as práticas. Motriz, Rio Claro, v.11 n. 3, p.185-197, set/dez. 2005.

VENLIOLES, Fábio Motta. Escola de futebol. Rio de Janeiro: Sprint, 2001.

Recebido em 30/09/2019

Aprovado em: 30/10/2019 